\title{
DESALINATION
}

\section{Adsorption of humic acid onto pillared bentonite}

\author{
Xianjia Peng, Zhaokun Luan*, Futai Chen, Binghui Tian, Zhiping Jia \\ State Key Laboratory of Environmental Aquatic Chemistry, Research Center for Eco-Environmental Sciences, \\ Chinese Academy of Sciences, Beijing 100085, China \\ Tel.+86(10)6284-9198; Fax:+86(10)6284-9198; email: luanzk@mail.rcees.ac.cn
}

Received 2 March 2004; accepted 8 September 2004

\begin{abstract}
Pillared bentonite, a clean and cost-effective adsorbent with high specific areas of $111.3 \mathrm{~m}^{2} / \mathrm{g}$ and high basal spacing of $1.98 \mathrm{~nm}$, was prepared for the removal of humic acid from water. It is effective for the removal of humic acid with a high adsorption capacity of $537 \mathrm{mg} / \mathrm{g}$, and adsorption is favored under acid conditions. Adsorption is dependent on ionic strength and dissolved $\mathrm{NaCl}$ enhanced adsorption. Over $97 \%$ removal was observed under natural $\mathrm{pH}$ conditions from humic acid solutions containing $10 \mathrm{mg} / \mathrm{L} \mathrm{Ca}^{2+}$ or $\mathrm{Mg}^{2+}$, which suggests that pillared bentonite can be an effective adsorbent for the removal of humic acid for drinking water purification. Pillared bentonite can be regenerated with $\mathrm{NaOH}$, and the regeneration efficiency reaches $83 \%$ and $85 \%$ when the concentration of $\mathrm{NaOH}$ reaches 0.025 and $0.05 \mathrm{~mol} / \mathrm{L}$. The mechanism for adsorption of humic acid to pillared bentonite is discussed.
\end{abstract}

Keywords: Pillared bentonite; Humic acid; Adsorption; Water purification; Montnorillonite

\section{Introduction}

Humic substances, which are present in natural waters (such as lakes, groundwater, and rivers), adversely affect water quality in several ways: causing undesirable color and taste, serving as food for bacterial growth in water distribution systems, binding with heavy metals and biocides (pesticides and herbicides) to yield high concentrations of these substances and enhance their transportation in water, and reacting with chlorine

*Corresponding author. in water treatment to produce trihalomethanes, which are known to be human carcinogens [1]. Coagulation/flocculation, filtration, adsorption, ion exchange, oxidation, biofiltration and even membrane filtration techniques have been developed to remove these substances [2]. Coagulation has been widely used, but it incurs a high operational cost and produces additional solid waste. Ion-exchange regenerates contain high amounts of salt and humic substances. Membrane processes produce a liquid concentrate and humic substances tend to foul membranes seriously and thus limit membrane application in this field

0011-9164/05/\$- See front matter (C) 2005 Elsevier B.V. All rights reserved

doi:10.1016/j.desal.2004.09.007 
$[1,2]$. Searching for a process that reduces waste disposal problems but is as effective and as easy to run as granular media filters led to the application of the adsorption process. Activated carbon, which has high surface areas, is the most widely used adsorbent in water treatment. Although it can be regenerated by thermal desorption or combustion in air, a substantial fraction of the carbon is lost with each oxidation cycle. This loss is a major economic consideration in any large-scale remediation application [3]. In this paper a kind of adsorbent, which was prepared from cost-effective natural bentonite, was studied for the removal of humic acid from water.

Bentonite is primarily composed of montmorillonite. It is a 2:1 type of clay mineral, and its unit layer structure consists of one $\mathrm{Al}^{3+}$ octahedral sheet placed between two $\mathrm{Si}^{4+}$ tetrahedral sheets. In the tetrahedral sheets, $\mathrm{Al}^{3+}$ can be substituted for $\mathrm{Si}^{4+}$; in the octahedral sheets, $\mathrm{Mg}^{2+}$ can be substituted for $\mathrm{Al}^{3+}$. These isomorphous substitutions in the mineral lattice cause a net negative charge at the clay-mineral surface. Typically, inorganic cations (e.g., $\mathrm{H}^{+}, \mathrm{Na}^{+}, \mathrm{Ca}^{2+}$ ) offset this charge imbalance on the external and internal surface of montmorillonite crystals [4]. These cations are exchangeable. By the exchange of these cations with certain other kinds of cations, bentonite can be modified. Since the discovery about their unique adsorption capacity in the 1950s, modified bentonites have been a subject of a number of studies as adsorbents for the removal of pollutants from water. For the removal of organic pollutants, bentonites are often modified by quaternary ammonium cations [5-9]. In aqueous solution large quaternary ammonium organic cations readily replace the inorganic cations in the intermellar space of montmorillonites by ion exchange, and the bentonites are said to be intercalated. The resulting organic cation-substituted bentonite is called "organobentonite". For the removal of organic pollutants, organobentonites have two disadvantages. First, because of the expansion of the mineral and the electrostatic repulsion between the negatively charged particles, organobentonites are suspended well in the solution, and the separation of adsorbent from water after adsorption becomes very difficult. Second, a small amount of organic cations will be released in the adsorption process and secondary pollution may occur. In order to solve these problems, new modified bentonites should be developed.

In this study a pillared bentonite (PB), which is not expansible and less charged, was prepared. Because it contains no organic matter, no hazardous substances are released in the adsorption process. A simplified scheme showing the pillaring of bentonite is illustrated in Fig. 1. The exchangeable cations were replaced by large aluminum polycation. After calcinations, the montmorillonite lamellae are permanently propped open by pillars of alumina, leading to microporosity. This material has relatively high surface areas, increased interlamellar spaces,

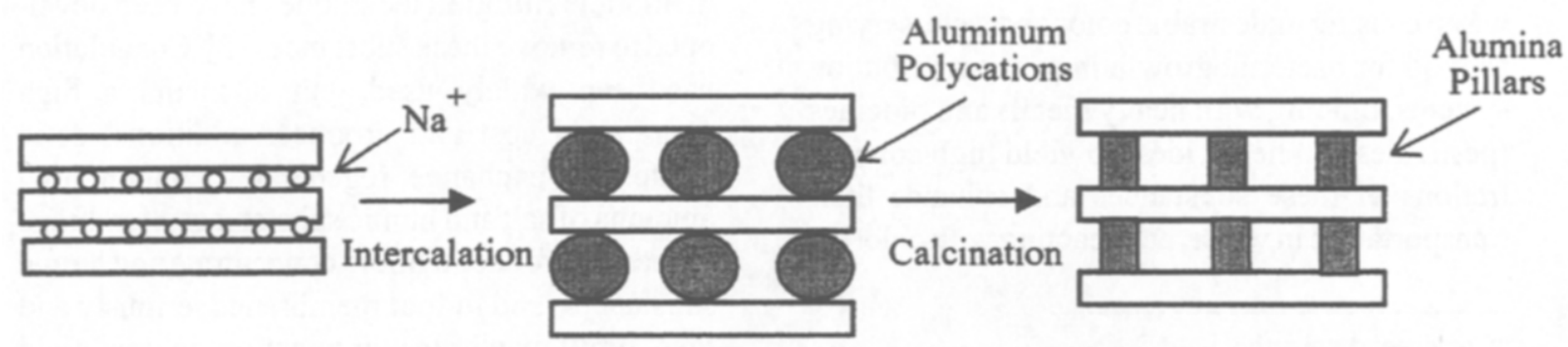

Fig. 1. Preparation of PB: intercalation of aluminum polycation followed by calcinations to generate the pillar. 
uniformly sized pores, and no longer swell or disperse in aqueous media. This makes the material a potential adsorbent as favorable adsorption sites are created [10]. The use of pillared bentonite for the removal of humic acid has been previously studied very little and is the topic of the present investigation. In this paper PB is reported to have a high adsorption capacity for humic substances from water and can be easily regenerated with sodium hydroxide after adsorption.

\section{Experimental}

\subsection{Preparation of $P B$}

The procedure followed to prepare $\mathrm{PB}$ is illustrated in Fig. 2.

A natural $\mathrm{Ca}^{2+}$ bentonite was used as the starting clay. It was exchanged to the sodium form before the pillaring reaction by a $4 \% \mathrm{Na}_{2} \mathrm{CO}_{3}$ solution at a $\mathrm{Na}_{2} \mathrm{CO}_{3}$ /bentonite ratio of $4 / 100$. The resulting $\mathrm{Na}$-bentonite was then dried, milled (particle size: $<0.075 \mathrm{~mm}$ ) and swollen in water for $24 \mathrm{~h}$ at room temperature. The pillaring solution was prepared by adding $0.5 \mathrm{M} \mathrm{NaOH}$ drop by drop to $0.2 \mathrm{M} \mathrm{AlCl}_{3}$ at $85^{\circ} \mathrm{C}$ with vigorous stirring. The ratio of $\mathrm{NaOH} / \mathrm{AlCl}_{3}$ was 2.4. The resulting solution was aged for $72 \mathrm{~h}$ before being used. PB was synthesized by adding the aged

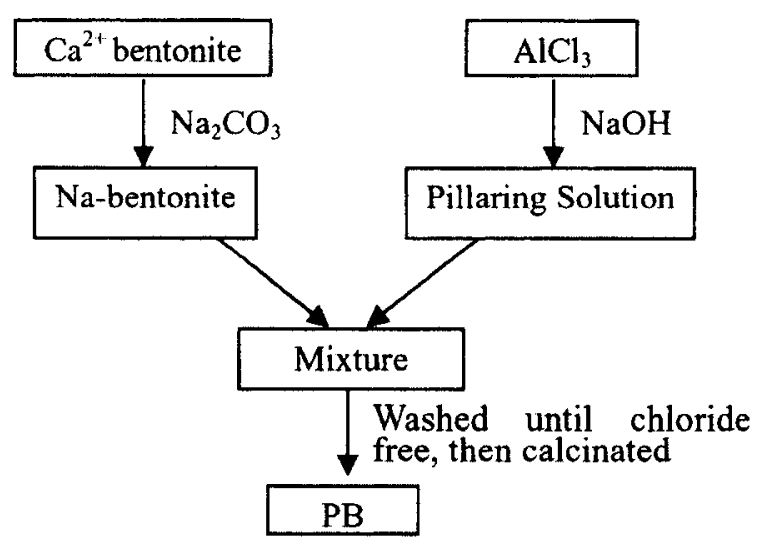

Fig. 2. Preparation pathway for PB. aluminum pillaring solution drop by drop to a $1.5 \%$ Na-bentonite suspension at room temperature with vigorous stirring. The ratio of aluminum to bentonite was $10 \mathrm{mmol} / \mathrm{g}$. The mixture is then centrifuged and washed with deionized water until it was chloride free. The suspension was calcinated and milled (particle size $<0.075 \mathrm{~mm}$ ). The product obtained was used as adsorbent.

\subsection{Characterization of $P B$}

Zeta potential and points of zero charge (PZC) for the adsorbent were determined by microelectrophoresis using a Malven model Zetasizer 2000 zeta potential analyzer. The zeta potentials of the adsorbents suspensions containing $0.02 \%$ solid in $0.01 \mathrm{M} \mathrm{NaCl}$ were determined at various $\mathrm{pH}$ values. The PZCs were obtained by interpolating the data to zero zeta potential. Specific surface areas (SSA) were determined according to the Brunaur-Emmet-Teller protocol on a Micromeritics (model ASAP 2000), accelerated surface area and porosimetry. Crystallization states of the adsorbents and the basal spacing between adjacent layers were determined by X-ray diffraction (XRD) analysis with a Rikaku Dmax-RB diffractometer.

\subsection{Adsorption and desorption experiments}

Humic acid was obtained as a commercial reagent grade solid from Aldrich. Before the adsorption test, the humic acid stock solution was prepared by dissolved a certain amount of humic acid in a known volume of deionized water. Batch adsorption experiments were performed in glass bottles. To each bottle, $50 \mathrm{~mL}$ humic acid solution of prescribed concentration and adsorbent were added. The $\mathrm{pH}$ was adjusted using $1 \mathrm{M} \mathrm{HCl}$ or $1 \mathrm{M} \mathrm{NaOH}$. The bottles were capped with glass screws and then the mixtures were stirred with a magnetic stirrer at $20^{\circ} \mathrm{C}$. For comparison, the use of $\mathrm{Na}$-bentonite for humic acid adsorption was also included. After equilibrium 
the solution was centrifuged and the supernatant solution was analyzed spectrophotometrically using a Hitachi model U-3010 doubling beam UV/visible spectrophotometer at $254 \mathrm{~nm}$. Matched 10-mm quartz cells were used. Humic acid adsorbed was calculated as follows:

$q=\left(C_{0}-C_{t}\right) V / m$

where $q$ is the humic acid adsorbed $(\mathrm{mg} / \mathrm{g}), C_{0}$ is the initial concentration of humic acid $(\mathrm{mg} / \mathrm{L}), \mathrm{C}_{\mathrm{t}}$ is the concentration of humic acid after being shaken for a certain period of time $(\mathrm{mg} / \mathrm{L}), V$ is the solution volume (L); and $m$ the adsorbent dosage (g).

Desorption experiments using $\mathrm{NaOH}$ were carried out. First humic acid was adsorbed according to the same procedure described above. After adsorption, suspensions were centrifuged. The supernatant was decanted and analyzed for humic acid. Then $25 \mathrm{~mL}$ of $\mathrm{NaOH}$ solution $(0.005-0.05 \mathrm{M})$ were added to the loaded particles. Samples were stirred with a magnetic stirrer at $20^{\circ} \mathrm{C}$ for $2 \mathrm{~h}$. The samples were centrifuged and the supernatant was analyzed for humic acid. Regeneraton efficiency was calculated.

\section{Results and discussion}

\subsection{Characterization of $P B$}

The zeta potentials of raw bentonite (RB), Nabentonite $(\mathrm{NB})$ and pillared bentonite $(\mathrm{PB})$ at various $\mathrm{pH}$ values are shown in Fig. 3. As can be seen, in the $\mathrm{pH}$ range from 3.2-6.8, $\mathrm{PB}$ has much higher zeta potentials than RB and NB, which indicates that montmorillonite is much less negatively charged after intercalation. Upon heating, the aluminum polycations intercalated into the intermellar space were dehydrated, and oxide pillars formed between montmorillonite layers. Thus, the exchangeable cations are significantly reduced and its zeta potentials increase. The PZC of PB occurs at $\mathrm{pH}$ 5.5. Zeta potentials

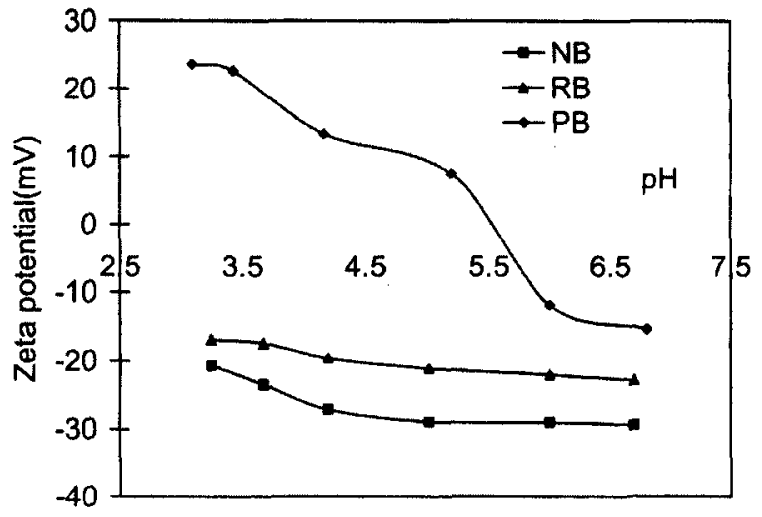

Fig. 3. Zeta potentials of $\mathrm{RB}, \mathrm{NB}$ and $\mathrm{PB}$.

Table 1

The SSAs and $d_{(0 o l)}$ of the RB, NB and PB

\begin{tabular}{llc}
\hline Sample & $d_{(001)}(\mathrm{nm})$ & $\mathrm{SSA}\left(\mathrm{m}^{2} / \mathrm{g}\right)$ \\
\hline $\mathrm{RB}$ & 1.62 & 33.71 \\
$\mathrm{NB}$ & 1.31 & 5.06 \\
$\mathrm{~PB}$ & 1.98 & 111.3 \\
\hline
\end{tabular}

of $\mathrm{PB}$ are positive for $\mathrm{pH}$ below 5.5, which indicates that the particles are positively charged, and negative for $\mathrm{pH}$ over 5.5, which indicates that the particles are negatively charged. Zeta potentials of $\mathrm{RB}$ and $\mathrm{NB}$ are negative over the $\mathrm{pH}$ range from 3.2-6.8, and decrease slightly with the increase in $\mathrm{pH}$. Because of its much higher zeta potentials than RB and NB, PB can be expected to reduce the repulsion between its particles and negatively charged substances and enhance the removal of these substances from liquid solutions.

The SSAs and $d_{(001)}$ basal spacing of the three materials are reported in Table 1. As shown in the table, after intercalation the $d_{(001)}$ basal spacing increases considerably, up to $1.98 \mathrm{~nm}$. The increased basal spacing between adjacent layers may create favorable adsorption sites in the microporous system. The SSA of PB is $111.3 \mathrm{~m}^{2} / \mathrm{g}$, which is much larger than that of RB and NB. This confirms the XRD results and suggests the formation of microporous system in the interlayer 


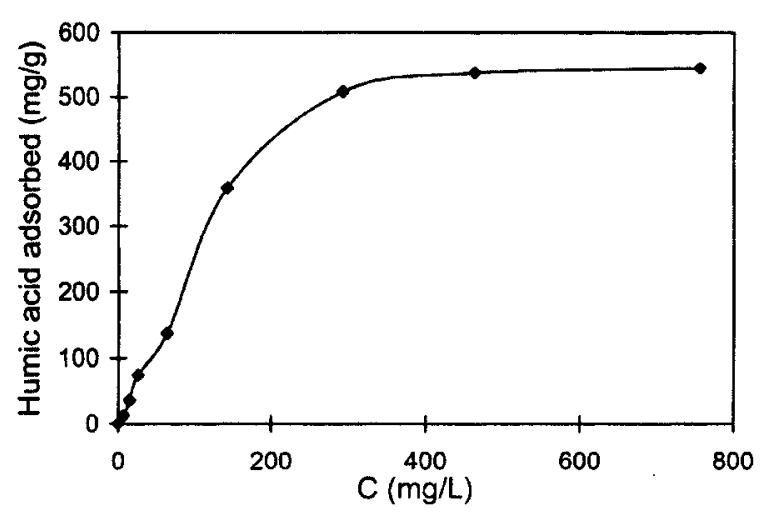

Fig. 4. Isotherm of humic acid adsorption to PB ( $m=$ $0.05 \mathrm{~g} ; \mathrm{pH}=4.0 ; t=24 \mathrm{~h}$ ).

spaces of the PB. As SSA increases, adsorption is favored.

\subsection{Adsorption of humic acid to $P B$}

The adsorption isotherm of PB was studied. The experiments were carried out by varying the initial humic acid concentration from 0 to $1300 \mathrm{mg} / \mathrm{L}$ with the initial $\mathrm{pH}$ of 4.0 . The results are shown in Fig. 4.

As can be seen from Fig. 4, the amount of humic acid adsorbed by PB increases with the increase in equilibrium concentration when $C<300 \mathrm{mg} / \mathrm{L}$. Subsequently, the amount of humic acid adsorbed increases gradually. It remains constant when the equilibrium concentration exceeds approximately $460 \mathrm{mg} / \mathrm{L}$ and a high adsorption capacity of $537 \mathrm{mg} / \mathrm{g}$, which indicates that $P B$ is very effective for humic acid removal. The Langmuir isotherm model was employed for adsorption of humic acid to PB:

$$
q=\frac{q_{m} K_{L} C}{1+K_{L} C}
$$

or

$$
\frac{1}{q}=\frac{1}{K_{L} q_{m}} \frac{1}{C}+\frac{1}{q_{m}}
$$

where $C$ is the equilibrium concentration, $q$ is the amount of humic acid adsorbed, $K_{L}$ and $q_{m}$ are Langmuir constants related to adsorption capacity and energy of adsorption respectively. The experimental data were approximated by Eq. (3) and can be fitted to the linearized Langmuir isotherm with a correlation coefficient of 0.9726 , reflecting a relatively high affinity between $\mathrm{PB}$ and humic acid, suggesting the occurrence of chemisorption. The ligand exchange mechanism occurring between PB and carboxylated groups of the humic acid molecules seems to play an important role in the process of humic acid adsorption.

In aqueous solution, the following proton shift reactions exist on the surface of $\mathrm{PB}$ [11-13]:

$$
\begin{aligned}
& \mathrm{AlOH}_{2}^{+}+\mathrm{H}_{2} \mathrm{O} \rightleftharpoons \mathrm{AlOH}+\mathrm{H}_{3} \mathrm{O}^{+} \\
& \mathrm{AlOH}+\mathrm{H}_{2} \mathrm{O} \rightleftharpoons \mathrm{AlO}^{-}+\mathrm{H}_{3} \mathrm{O}^{+} \\
& \mathrm{SiOH}_{2}^{+}+\mathrm{H}_{2} \mathrm{O} \rightleftharpoons \mathrm{SiOH}+\mathrm{H}_{3} \mathrm{O}^{+} \\
& \mathrm{SiOH}+\mathrm{H}_{2} \mathrm{O} \rightleftharpoons \mathrm{SiO}^{-}+\mathrm{H}_{3} \mathrm{O}^{+}
\end{aligned}
$$

The ligand exchange then may occur between carboxylated groups of the humic acid molecules and PB [13-15]:

$$
\begin{aligned}
& \mathrm{SOH}+{ }^{-} \mathrm{OOC}-\mathrm{HA} \rightleftharpoons \mathrm{SOOC}-\mathrm{HA}+\mathrm{OH}^{-} \\
& \mathrm{SOH}_{2}^{+}+{ }^{-} \mathrm{OOC}-\mathrm{HA} \rightleftharpoons \mathrm{SOOC}-\mathrm{HA}+\mathrm{H}_{2} \mathrm{O}
\end{aligned}
$$

where $S$ represents the surface of PB. The effect of $\mathrm{pH}$ on the adsorption of humic acid is shown in Fig. 5 where the amount of humic acid adsorbed to $\mathrm{PB}$ decreases with the increase in $\mathrm{pH}$. An increase in $\mathrm{pH}$ from 3.1 to 9.5 results in a decrease from $19.4 \mathrm{mg} / \mathrm{g}$ to $1.0 \mathrm{mg} / \mathrm{g}$ in the amount of humic acid adsorbed. The dependence of adsorption on $\mathrm{pH}$ values can be explained by two mechanisms: (1) $\mathrm{pH}$ of the solution affects the surface charge of $\mathrm{PB}$ and the ionization of humic acid. The higher the $\mathrm{pH}$, the greater the dissociation of the functional groups $-\mathrm{COOH}$ and $-\mathrm{COH}$ 


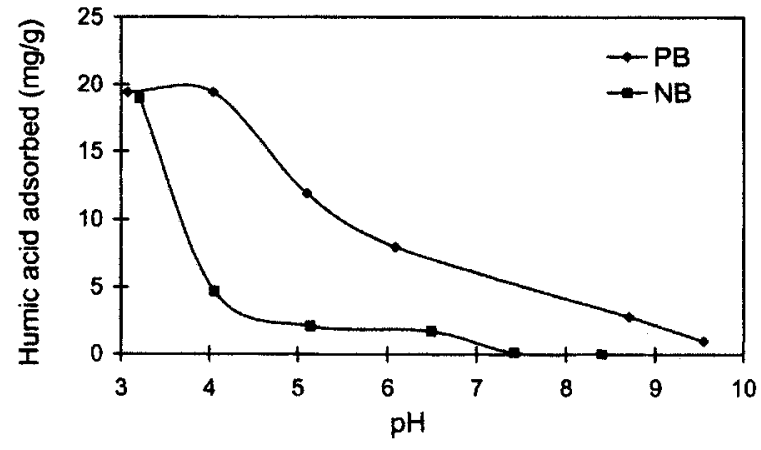

Fig. 5. The effect of $\mathrm{pH}$ on the adsorption of humic acid $\left(C_{0}=20 \mathrm{mg} / \mathrm{L} ; t=24 \mathrm{~h} ; m=0.05 \mathrm{~g}\right)$.

to $-\mathrm{COO}^{-}$and $\mathrm{CO}^{-}$. The net effect will result in an increase in negative charges on humic acid [16]. According to the results of the zeta-potential measurements, the positive charges on $\mathrm{PB}$ at lower $\mathrm{pH}$ values facilitate the adsorption of negatively charged humic acid. At higher $\mathrm{pH}$ values, the electrostatic interaction between the negative charges on PB and humic acid repels the humic acid from the surface of $\mathrm{PB}$ and the increase of negative charge densities on both pillared adsorbent and adsorbate with increasing $\mathrm{pH}$ results in the decrease in adsorption. (2) At lower $\mathrm{pH}$ values, carboxylate groups on the humic acid molecules are protonated, minimizing the intramolecular electrostatic repulsion and contracting the humic acid molecules. Humic acid may exist in a spherical structure at lower $\mathrm{pH}$ but exist in a rather linear or stretched structure at higher $\mathrm{pH}$ $[17,18]$. Decrease of the molecular volume can facilitate the adsorption process due to greater availability of pores where humic acid molecules can penetrate [19].

It can also be seen from Fig. 5 that adsorption of PB is much higher than that of NB. As discussed earlier, adsorption of humic acid to $\mathrm{PB}$ seems to be a charge-related adsorption phenomenon. Ionic strength is an important factor affecting the adsorption in such phenomena. Thus, the effect of ionic strength on adsorption was studied. The ionic strength of the solution

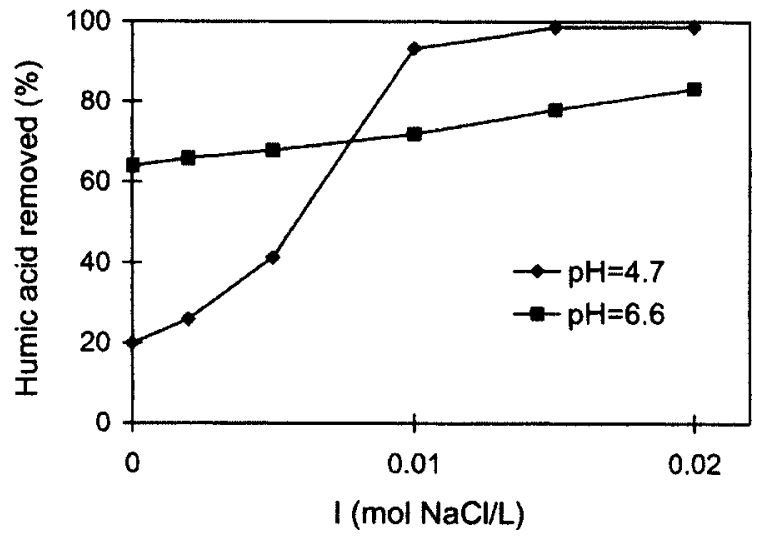

Fig. 6. The effect of ionic strength on adsorption ( $m=$ $0.03 \mathrm{~g}, t=24 \mathrm{~h}, C_{0}=20 \mathrm{mg} / \mathrm{L}$ at $\mathrm{pH} 6.6, C_{0}=50 \mathrm{mg} / \mathrm{L}$ at $\mathrm{pH}$ 4.7).

was adjusted with $\mathrm{NaCl}$. Two $\mathrm{pH}$ values of the solution, 4.7 and 6.6 , which were respectively below and above the PZC of PB, were selected. The results are shown in Fig. 6. As can be seen, an increase in ionic strength results in an increase in the adsorption at both $\mathrm{pH}$ values. The increase of adsorption with an increase in ionic strength can be explained by several mechanisms $[13,20]$ : (1) The addition of salt results in the compression of the diffuse double layer and charge neutralization, which would facilitate the ligand exchange mechanism. (2) The increase of ionic strength causes a decrease of molecular volume of humic acid due to minimization of the electrostatic repulsion between ionized oxygen groups. The decrease of molecular volume of the humic acids facilitates the adsorption. (3) At $\mathrm{pH}$ above PZC of PB particles, the electrostatic interactions between negatively charged $\mathrm{PB}$ particles and the negatively charged oxygen groups were repulsive. The addition of salt results in the screening of the surface charge of both adsorbent and adsorbate. Thus the electrostatic repulsion can be reduced by increasing the ionic strength of the solution due to this screening effect.

$\mathrm{Ca}^{2+}$ and $\mathrm{Mg}^{2+}$ always exist in natural water. In order to assess the potential application of PB for 

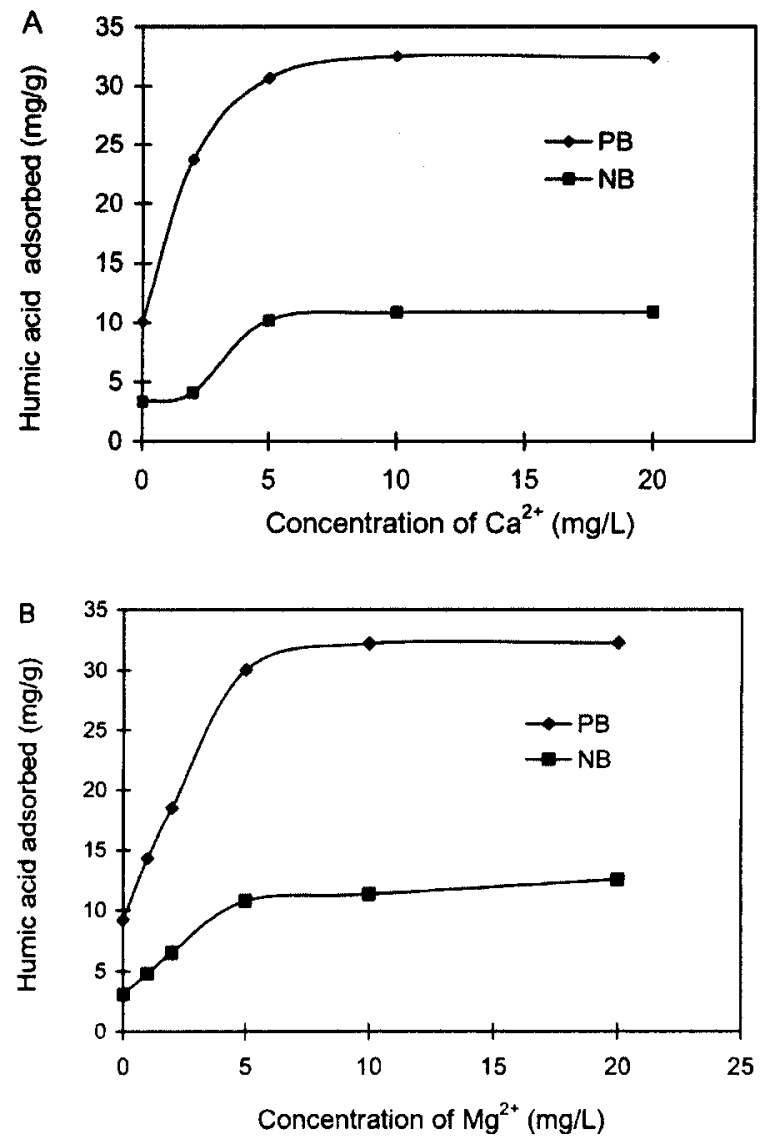

Fig. 7. Effect of $\mathrm{Ca}^{2+}$ and $\mathrm{Mg}^{2+}$ on adsorption $\left(C_{0}=\right.$ $20 \mathrm{mg} / \mathrm{L}, m=0.03 \mathrm{~g} ; t=24 \mathrm{~h}$ ). A: Effect of $\mathrm{Ca}^{2+}$. B: Effect of $\mathrm{Mg}^{2+}$.

the removal of natural organic matter from natural water, adsorption capacity was evaluated as a function of $\mathrm{Ca}^{2+}$ and $\mathrm{Mg}^{2+}$ concentration. The adsorbent is aimed to be used in the purification of drinking water, which is always in large quantities. In order to simplify the purification procedure, adsorption studies were carried out without $\mathrm{pH}$ adjustment. The $\mathrm{pH} 6.3$ of the mixture was measured. The results are shown in Fig. 7. It can be seen that $\mathrm{Ca}^{2+}$ and $\mathrm{Mg}^{2+}$ significantly enhanced the adsorption capacity of both NB and PB. An increase from 0 to $10 \mathrm{mg} / \mathrm{L}$ in the concentration of $\mathrm{Ca}^{2+}$ and $\mathrm{Mg}^{2+}$ results in an increase from 10 to 32.5 and $32.2 \mathrm{mg} / \mathrm{g}$ in the amount of humic acid adsorbed, respectively, by $P B$. When the concentrations of $\mathrm{Ca}^{2+}$ and $\mathrm{Mg}^{2+}$ reach $10 \mathrm{mg} / \mathrm{L}$, over $97 \%$ removal of humic acid was measured. These results show that PB can be an effective adsorbent for the removal of humic acid in drinking water purification.

The compression of the diffuse double layer and charge neutralization, the compression of the molecular volume of humic acid and the screening of the surface charge of both adsorbent and adsorbate by $\mathrm{Ca}^{2+}$ and $\mathrm{Mg}^{2+}$ may all contribute to the increase in adsorption. Otherwise, the following mechanisms can also result in increased adsorption [21-25]: (1) Interactions in solution between salts and organics to produce a change in the properties of organics. The bridging of $\mathrm{Ca}^{2+}$ and $\mathrm{Mg}^{2+}$ between humic acid molecules neutralizes the repulsive forces between them. (2) Interactions between salts and the adsorbent. $\mathrm{Ca}^{2+}$ and $\mathrm{Mg}^{2+}$ can link the pillared clay particle with humic acid, forming a clay-metal-humic acid complex or a clay-metal- $\mathrm{H}_{2} \mathrm{O}$-humic acid complex. The forming of these kinds of complexes can significantly enhance adsorption.

Fig. 8. shows the effect of contact time on adsorption. The removal increases with time in the first $40 \mathrm{~min}$, and adsorption reaches equilibrium at 40 min for both PB and NB. Humic acid adsorbed by $\mathrm{PB}$ and NB reaches $19.7 \mathrm{mg} / \mathrm{g}$ (98.4\% removal) and $4.0 \mathrm{mg} / \mathrm{g}(20 \% \mathrm{removal})$, respectively. The high removal percentage of PB suggests that it can be a promising adsorbent for the removal of humic acid from water.

As can be seen from above results, $\mathrm{PB}$ has a much higher adsorption capacity than NB. This is due to several reasons. (1) Intercalation significantly enhanced the SSA of bentonite, and thus enhanced the contact opportunities of humic acid with adsorbent. (2) PB is much less negatively charged than NB, and the repulsion between its particles and humic acid is largely reduced. (3) According to Schulthess and Huang's report [25], a strong adsorption of humic acid occurs on the $\mathrm{Al}$ sites and a weak adsorption occurs on the 


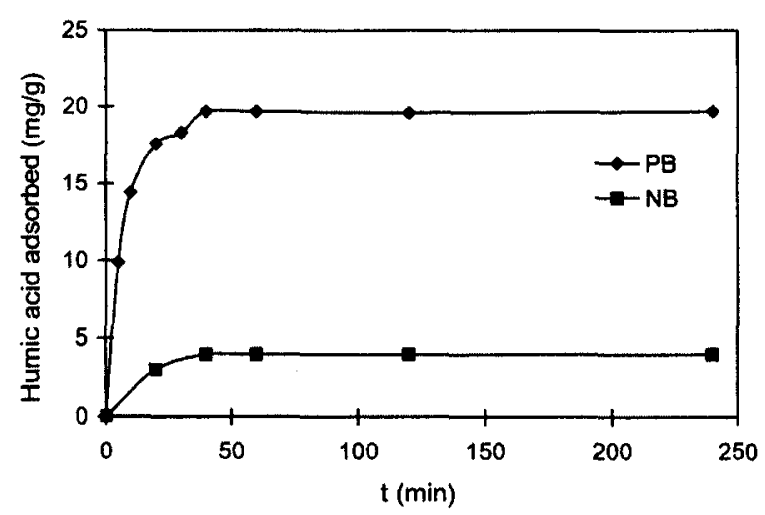

Fig. 8. Effect of contact time on adsorption $\left(C_{0}=20 \mathrm{mg} /\right.$ $\mathrm{g}, m=0.05 \mathrm{~g}, \mathrm{pH}=4.0$ ).

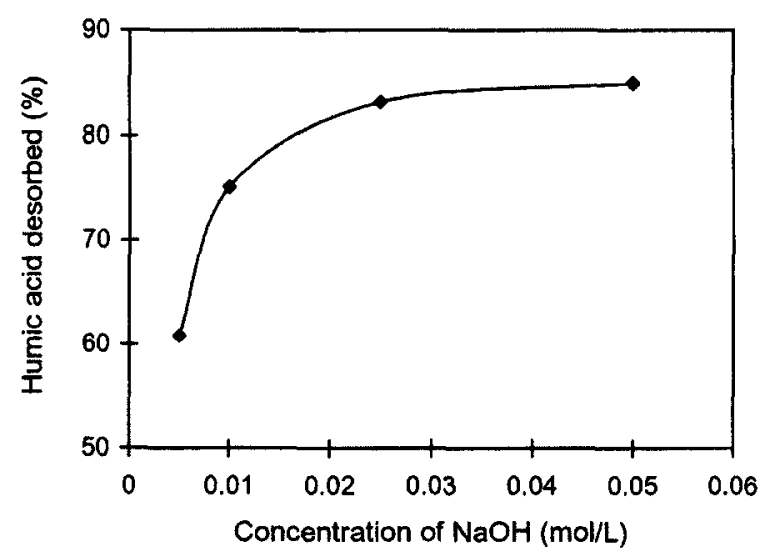

Fig. 9. Effect of $\mathrm{NaOH}$ concentration on desorption of humic acid.

$\mathrm{Si}$ sites of clays. That is to say, $\mathrm{Al}$ oxides are effective adsorption sites for humic acid. The intercalation process introduces $\mathrm{Al}_{2} \mathrm{O}_{3}$ pillars between the layers of montmorillonite and thus the number of effective adsorption sites increases.

\subsection{Desorption}

The applicability of $\mathrm{PB}$ as a potential adsorbent depends not only on the adsorption capacity, but also on the desorption property and reusability. A NaOH solution was selected as the regeneration agent in the present work. In the desorption experiments, in order to show the desorption property of $\mathrm{PB}$ as an adsorbent for the purification of natural water, first humic acid was adsorbed from a $20 \mathrm{mg} / \mathrm{L}$ solution containing $10 \mathrm{mg} / \mathrm{L} \mathrm{Ca}^{2+}$. The effect of $\mathrm{NaOH}$ concentration on desorption efficiency is plotted in Fig. 9. It can be seen that diluted $\mathrm{NaOH}$ is efficient for the regeneration of $\mathrm{PB}$. The regeneration efficiency reaches $83 \%$ and $85 \%$ when the concentration of $\mathrm{NaOH}$ reaches 0.025 and $0.05 \mathrm{~mol} / \mathrm{L}$.

\section{Conclusions}

Aluminum polycation PB was successfully prepared and is reported to be an effective adsorbent for the removal of humic acid from water. It has much higher zeta potential than raw bentonite and $\mathrm{Na} a$-bentonite. The specific area and basal spacing reaches $111.3 \mathrm{~m}^{2} / \mathrm{g}$ and $1.98 \mathrm{~nm}$, respectively, which indicates the formation of a microporous system in the interlayer spaces of the PB. The adsorption properties of PB for humic acid depend on $\mathrm{pH}$ values. Adsorption is favored under acid conditions. PB is effective for the removal of humic acid with a high adsorption capacity of $537 \mathrm{mg} / \mathrm{g}$. It has a much higher adsorption capacity than Na-bentonite because it has a higher zeta potential and specific area and the introduced $\mathrm{Al}_{2} \mathrm{O}_{3}$ pillars between the layers are effective adsorption sites for humic acid. Adsorption is dependent on ionic strength and dissolved $\mathrm{NaCl}$ enhanced adsorption. $\mathrm{Ca}^{2+}$ and $\mathrm{Mg}^{2+}$ in the solution significantly enhanced the adsorption. When $\mathrm{Ca}^{2+}$ and $\mathrm{Mg}^{2+}$ reach $10 \mathrm{mg} / \mathrm{L}$, over $97 \%$ removal of humic acid was observed under natural $\mathrm{pH}$ conditions, which suggest that $P B$ can be an effective adsorbent for the removal of humic acid in drinking water purification. The increase of adsorption with the increase of ionic strength and dissolved salt is probably due to the compression of the diffuse double layer and charge neutralization, the compression of the molecular volume of humic acid and the screen- 
ing of the surface charge of both adsorbent and adsorbate by the added salt. Otherwise, interactions in solution between salts and organics to produce a change in the properties of organics and the formation of a clay-metal-humic acid complex or clay-metal- $\mathrm{H}_{2} \mathrm{O}$-humic acid complex can also contribute to increased adsorption with the addition of $\mathrm{Ca}^{2+}$ and $\mathrm{Mg}^{2+}$. $\mathrm{PB}$ can be regenerated with $\mathrm{NaOH}$. The regeneration efficiency reaches $83 \%$ and $85 \%$ when the concentration of $\mathrm{NaOH}$ reaches 0.025 and $0.05 \mathrm{~mol} / \mathrm{L}$.

\section{References}

[1] R. Bai and X. Zhang, J. Colloid Interf. Sci., 243 (2001) 52-60.

[2] I.P. Teermann and M.R. Jekel, Water Sci. Tech., 40(9) (1999) 199-206.

[3] T.G. Danis, T.A. Albanis, D.E. Petrakis and P.J. Pomonis, Water Res., 32(2) (1998) 295-302.

[4] J.A. Smith and A. Galan, Environ. Sci. Technol., 29(3) (1995) 685-692.

[5] L. Zhu, Y. Li and J. Zhang, Environ. Sci. Technol., $31(5)(1997)$ 1407-1410.

[6] J.J. Deitsch, J.A. Smith, M.B. Arnold and J. Bolus, Environ. Sci. Technol., 32(20) (1998) 3169-3177.

[7] J.A. Smith and P.R. Jaffé, Environ. Sci. Technol., 25(12) (1991) 2054-2058.

[8] S. Gitipour, M.T. Bowers, W. Huff and A. Bodocsi, Spill. Sci. Technol. Bull., 4(3) (1997) 155-164.

[9] L. Zhu, X. Ren and S. Yu, Environ. Sci. Technol., 32(21) (1998) 3374-3378.
[10] V. Lenoble, O. Bouras, V. Deluchat, B. Serpaud and J.C. Bollinger, J. Colloid Interf. Sci., 255 (2002) 52-58.

[11] M.B. McBride, Environmental Chemistry of Soils, Oxford University Press, Oxford, 1994.

[12] P.W. Schindler and W. Stumm, in: W. Stumm, ed., Aquatic Surface Chemistry, Wiley, New York, 1987.

[13] G. Abate and J.C. Masini, Coll. Surf., 226 (2003) 25-34.

[14] E.M. Murphy and J.M. Zachara, Geoderma, 67 (1995) 103-124.

[15] G. Sposito, The Chemistry of Soils, Oxford University Press, Oxford, 1989.

[16] A. Liu and R.D. Gonzalez, J. Coll. Interf. Sci., 218 (1999) 225-232.

[17] A.W.P. Vermeer, W.H. van Riemsdijk and L.K. Koopal, Langmuir, 14 (1998) 2810-2819.

[18] M.N. Jones and N.D. Bryan, Adv. Coll. Interf. Sci., 78 (1998) 1-48.

[19] M. Bjelopavlic, G. Newcombe and R. Hayes, J. Coll. Interf. Sci., 210 (1999) 271-280.

[20] X. Zhang and R. Bai, J. Coll. Interf. Sci., 264 (2003) 30-38.

[21] S.J. Randtke and C.P. Jepsen, J. AWWA, 74 (1982) 84-93.

[22] E.K. Kim and H.W. Walker, Coll. Surfaces A, 194 (2001) 123-131.

[23] H.G.M. van de Steeg, M.A.C. Stuart, A. de Keizer, and B.H. Bijsterbosch, Langmuir, 8 (1992) 25382546.

[24] A.W.P. Vermeer, F.A.M. Leermakers and L.K. Koopal, Langmuir, 13 (1997) 4413-4421.

[25] C.P. Schulthess and C.P. Huang, Soil Sci. Soc. Am. J., 55 (1991) $34-42$. 